\title{
Comparison of Tests Used in Malnutrition in Hospitalized Geriatric Patients, Relationship with Anthropometric Measurements and Hand Grip Strength
}

\author{
(1) Hakan Yavuzer1, (1) Tuğçe Emiroğlu1, (1) Erol Demir2, (1) Abdulkadir Erçalışkan³, (1) Alper Döventaş¹, (1) Deniz Suna Erdinçler1 \\ 1 İstanbul University-Cerrahpaşa, Cerrahpaşa Faculty of Medicine, Department of Geriatrics, İstanbul, Turkey \\ 2 istanbul University Faculty of Medicine, Department of Nephrology, Istanbul, Turkey \\ 3istanbul University-Cerrahpaşa, Cerrahpaşa Faculty of Medicine, Department of Hematology, istanbul, Turkey
}

\begin{abstract}
Objective: There is no single test and recommended method ideal for nutritional risk assessment in hospitalized elderly patients. In this study, we intended to screen hospitalized elderly patients for malnutrition by using two tests and compare the results with anthropometric measurements and hand grip strength test and describe the relationship between them.
\end{abstract}

Materials and Methods: In this study, we evaluated 200 hospitalized patients aged 60 years and over in the internal medicine, cardiology and Infectious diseases departments. We applied nutritional risk screening (NRS 2002) with the hand grip test and the mini nutritional assessment (MNA). Body Mass index and upper arm and calf circumference measurements were recorded. Chi-square and ANOVA test were used for statistical analyses.

Results: Of the 200 patients, 98 were female and 102 were male. The mean age was $71.3 \pm 8.1$ years. According to the NRS-2002, the prevalence of malnutrition risk was 34\%; according to the MNA, the prevalence of malnutrition was $23.5 \%$, and the prevalence of malnutrition risk was $27.5 \%$. According to the NRS-2002, 38\% of the patients at risk for malnutrition were female and $62 \%$ were male $(p=0.029)$. The relationship between hand grip test and Mini Nutritional Assesment (MNA) was statistically significant $(p<0.0001)$.

Conclusion: We suppose that the MNA test which was used for screening of malnutrition in outpatient setting can be used for hospitalized patients as NRS 2002, and we suggest that anthropometric measurements and hand grip test would be reliable tools for sarcopenia as malnutrition screening and assessment.

Keywords: Aged, malnutrition, inpatient

\section{Introduction}

Due to the increase in the elderly population in the world, the health problems in old age and the studies on the solution of these problems are increasing day by day $(1,2)$. Nutritional status is also an important determinant of health in people over 65 years of age. In the 2006 European Society of Clinical Nutrition and Metabolism (ESPEN) guide, malnutrition as terminology; energy, protein and other nutrients as a result of a deficiency or excess (ie, imbalance), tissue/body form (shape, size and composition) and function is defined as a condition that can cause measurable negative effects and clinical consequences (3). Malnutrition is one of the important determinants of morbidity and mortality in the elderly. Malnutrition is associated with increased hospitalization time, impaired quality of life, delayed wound healing, negative health conditions such as infection and decreased functional capacity. The prevalence of malnutrition was found to be $5-10 \%$ in the elderly living at home, 30-60\% in the elderly living in the nursing home and 35$65 \%$ in the elderly in the hospital (4). Although there are many

Address for Correspondence: Tuğçe Emiroğlu, İstanbul University-Cerrahpaşa, Cerrahpaşa Faculty of Medicine, Department of Geriatrics, İstanbul, Turkey

Phone: +90 5053263634 E-mail: tugceemiroglu@yahoo.com.tr ORCID: orcid.org/0000-0002-5550-6477

Received: Sept 20, 2019 Accepted: Dec 24, 2019

Cite this article as: Yavuzer A, Emiroğlu T, Demir E, Erçalışkan A, Döventaş A, Erdinçler DS. Comparison of Tests Used in Malnutrition in Hospitalized Geriatric Patients, Relationship with Anthropometric Measurements and Hand Grip Strength. Eur J Geriatr Gerontol 2020;2(1):3-8

๑Copyright 2020 by the Academic Geriatrics Society / European Journal of Geriatrics and Gerontology published by Galenos Publishing House. 
instruments for screening and diagnosis of malnutrition, it is known that the diagnosis of malnutrition is mostly overlooked in practice $(5,6)$. Screening and diagnostic instruments are important in the recognition of the patient with malnutrition, in finding the underlying causes of malnutrition and in evaluating the results of malnutrition $(6,7)$. Unfortunately, there is no gold standard for the detection of malnutrition in elderly patients. Diagnostic criteria for malnutrition according to ESPEN criteria;

- Alternative 1 : Body Mass index (BMI) $<18.5 \mathrm{~kg} / \mathrm{m}^{2}$,

- Alternative 2:

- Weight loss (unintentional) $>10 \%$ indefinite of time, or $>5 \%$ over the last 3 months combined with either

- $\mathrm{BMI}<20 \mathrm{~kg} / \mathrm{m}^{2}$ if $<70$ years of age, or $<22 \mathrm{~kg} / \mathrm{m}^{2}$ if $>70$ years of age or

- Fat Free Mass index $<15$ and $17 \mathrm{~kg} / \mathrm{m}^{2}$ in women and men, respectively (8).

Malnutrition-associated sarcopenia; it is a phenotype that originates from malnutrition regardless of the cause (impairment of oral intake, malabsorption, and increased catabolism) (9). There is a decrease in fat mass as well as muscle mass.

The European Society of Parenteral and Enteral Nutrition recommends screening for nutritional status with Mini Nutritional Assesment (MNA) in elderly outpatients and screening with NRS 2002 (Nutritional Risc score 2002) in inpatients. Because the NRS 2002 test is a subjective test, it is predicted that MNA will be more appropriate for inpatients.

Therefore, in our study, the comparison of these two tests used in the screening of malnutrition in elderly hospitalized patients, the relationship with anthropometric measurements and hand grip strength were evaluated. Thus, it is aimed to show that these parameters can be used in sarcopenia and malnutrition screening.

\section{Materials and Methods}

\section{Working Design}

Between December 2011 and December 2012, 253 patients aged 60 years and older who were hospitalized in Cerrahpaşa Medical Faculty Internal Medicine, cardiology and infectious disease services were evaluated. Fifty-three patients were excluded because they did not meet the study criteria. Patients with hemiplegic, hypervolemic patients (CHF, Nephrotic syndrome), advanced stage dementia, Parkinson's disease, history of previous cerebrovascular accident, hand dysfunction, walking disorder were not included in the study. 200 patients were included in the study with consent forms.

Age, gender, weight, height and BMI values of the patients were recorded. The days of hospitalized, the number of diseases, the number of drugs used, the presence of incontinence, the presence of urinary catheter, whether alcohol, cigarette smoking, regular exercise, the number of falls in the last one year, fracture history, the presence of pressure ulcers, nutritional support treatment was questioned.

Istanbul University Cerrahpaşa Faculty of Medicine Clinical Research Ethics Committee was approved with the decision number 1834 dated 18.03.2013.

\section{Nutritional Evaluation}

All patients were evaluated by two unaware researchers. While a researcher is performing MNA short form (MNA-SF) and long form, NRS-2002 nutritional screening and hand grip tests were performed by the other researcher on the same day or the following day.

In the MNA-SF; normal was accepted 12 or higher points, the risk of malnutrition was 11 or less, malnutrition was seven or less. In MNA; normal was accepted 24 points and above; malnutrition risk between 17 and 23.5 points, malnutrition was below 17 points.

In the NRS 2002 Screening test, below three points were normal; it was accepted as a malnutrition risk of three and above.

\section{Evaluation of Hand Grip Strength and Anthropometric Measurements}

Jamar hand dynamometer was used to determine hand grip the strength. The dominant hand was determined by asking the patients which hand they used actively. The patients were placed in the chair and the elbows were placed on the table and their arms were held parallel to the floor by 90 degrees flexion; three measurements were made with one minute rest periods from both the right and left arms. Three measurements were averaged. Measurements below $30 \mathrm{~kg}$ in males and $20 \mathrm{~kg}$ in females were accepted as de low muscle strength. Patients were divided into two groups with low muscle strength and normally as two groups.

Upper arm circumferences (UAC) and calf circumferences (CC) were measured. The patients were normal $25 \mathrm{~cm}$ and above according to the UAC; According to $\mathrm{CC}$, they were grouped as normal of $31 \mathrm{~cm}$ and above.

Weight, height measurements and BMI of the patients were performed. We were accepted $\mathrm{BMI}>27 \mathrm{~kg} / \mathrm{m}^{2}$ overweight, between $27-22 \mathrm{~kg} / \mathrm{m}^{2}$ normal and $<22 \mathrm{~kg} / \mathrm{m}^{2}$ weak.

\section{Statistics}

All data of our study were analysed using SPSS software (SPSS Inc., Chicago, IL) version 16.0. Variables (age, gender, weight, height, BMI, number of days of outpatient treatment, number 
of diseases, number of drugs used) were defined as mean standard deviation, minimum, maximum, median, interquartile range (IQR-inter quartile range). One-way Analysis of Variance test was used for comparison of continuous variables (MNASF and MNA score) between groups (NRS-2002 and hand grip strength). Tukey HSD (Tukey's Honestly Significant Difference test) method was used as post hoc evaluation. Student t-test and corrected t-test were used for comparison of independent groups (age, weight, height, BMI, UAC, CC, Hand Grip test, number of drugs used, number of additional diseases, number of falls, NRS-2002 score, MNA-SF score, MNA score). In the comparison of categorical variables (MNA score, NRS-2002 score, Hand Grip test, UAC, CC), chi-square test or Fisher exact test was applied. Continuous values were expressed as mean and standard deviation.

\section{Results}

A total of 200 patients were included in the study as $98(49 \%)$ were female and $102(51 \%)$ were male. The mean age of women was $71.3 \pm 8.1$ and males were $70.9 \pm 7.6$. Demographic data by sex are given in Table 1. There was no significant difference between MNA-SF, MNA scores with sex. The NRS-2002 score was significantly higher in males $(\mathrm{p}=0.007)$.

Patients were divided into three groups according to MNASF score as normal, malnutrition risk and malnutrition. The risk of malnutrition was detected in 67 of the 200 patients (33.5\%) and malnutrition was detected in 56 patients $(28 \%)$. Seventy seven of the patients (38.5\%) had normal nutritional status. Twenty eight (50\%) of the patients with malnutrition were female and $28(50 \%)$ were male $(p=0.174)$. Patients were divided into three groups according to MNA score as

\begin{tabular}{|c|c|c|c|}
\hline & $\begin{array}{l}\text { Female } \\
(n=98)\end{array}$ & $\begin{array}{l}\text { Male } \\
(n=102)\end{array}$ & $\mathbf{p}$ \\
\hline Age & $71.3 \pm 8.1$ & $70.9 \pm 7.6$ & 0.7 \\
\hline Weight (kg) & $75.5 \pm 16.6$ & $77 \pm 16.3$ & 0.5 \\
\hline Height (cm) & $158.1 \pm 6.2$ & $169.5 \pm 7.5$ & $<0.001$ \\
\hline BMI $\left(\mathrm{kg} / \mathrm{m}^{2}\right)$ & $30.2 \pm 6.4$ & $26.6 \pm 5.8$ & $<0.001$ \\
\hline Upper arm circumference (cm) & $28.6 \pm 4.3$ & $26.6 \pm 3.4$ & $<0.001$ \\
\hline Calf circumference $(\mathrm{cm})$ & $32.1 \pm 4.3$ & $31.8 \pm 4.9$ & 0.7 \\
\hline Hand grip strength (kg) & $14.7 \pm 12.7$ & $25 \pm 16.5$ & $<0.001$ \\
\hline Number of drugs & $9.38 \pm 4.24$ & $8.88 \pm 4.3$ & 0.4 \\
\hline Number of diseases & $3.4 \pm 1.5$ & $3 \pm 1.8$ & 0.8 \\
\hline Number of falls & $1.36 \pm 2.2$ & $0.53 \pm 1.2$ & 0.001 \\
\hline MNA-SF & $9.8 \pm 3.3$ & $9.6 \pm 3.3$ & 0.6 \\
\hline MNA & $17.6 \pm 3.5$ & $18.4 \pm 5.3$ & 0.3 \\
\hline NRS-2002 & $1.41 \pm 1.54$ & $1.99 \pm 1.45$ & 0.007 \\
\hline \multicolumn{4}{|c|}{$\begin{array}{l}\text { BMI: Body Mass index, MNA-SF: Mini Nutritional Assesment-short form, MNA: Mini } \\
\text { Nutritional Assesment, NRS-2002: Nutritional Risc score } 2002\end{array}$} \\
\hline
\end{tabular}

normal, malnutrition risk and malnutrition. Fifty five of the 200 patients $(27.5 \%)$ had malnutrition risk, and 47 (23.5\%) had malnutrition. Ninety eight (49\%) of the patients were normal. Twenty four patients (51\%) with malnutrition were female and $23(49 \%)$ were males $(p=0.26)$.

Patients were divided into two groups as normal and malnutrition risk according to NRS-2002 Screening test. Malnutrition risk was detected in 68 (34\%) of 200 patients. One hundred thirty two $(66 \%)$ of the patients were included in the normal group. Forty two (61\%) of malnourished patients were male and $26(39 \%)$ were female. Malnutrition risk was significantly higher in males $(p=0.029)$.

The comparing NRS-2002 screening and MNA scores tests results with hand grip test are given Table 2. There was a significant relationship between MNA-SF and MNA tests and Hand Grip test $(p<0.001)$. However, there was no relation between NRS2002 and Hand Grip test $(p=0.511)$.

The relation between MNA and NRS 2002 tests with UAC and CC was given in Table 3. There was a significant relationship between MNA and NRS-2002 with the calf circumference $(p<0.001$ and $p=0.004$, respectively). There was also a significant relationship between MNA and NRS2002 and upper arm circumference $(p<0.001$ and $p=0.002$, respectively).

When MNA and NRS-2002 test results were compared; malnutrition risk was found in 30 of 47 patients who were malnourished with MNA. Malnutrition risk was detected in 22 of 55 patients who were malnutrition risk with MNA. Malnutrition risk was found in 16 of 98 patients who were found to be normal according to MNA. There was a significant relationship between MNA test and NRS-2002 test results $(p<0.001)$.

Table 2. The relationship between NRS-2002 and MNA test with hand grip strength

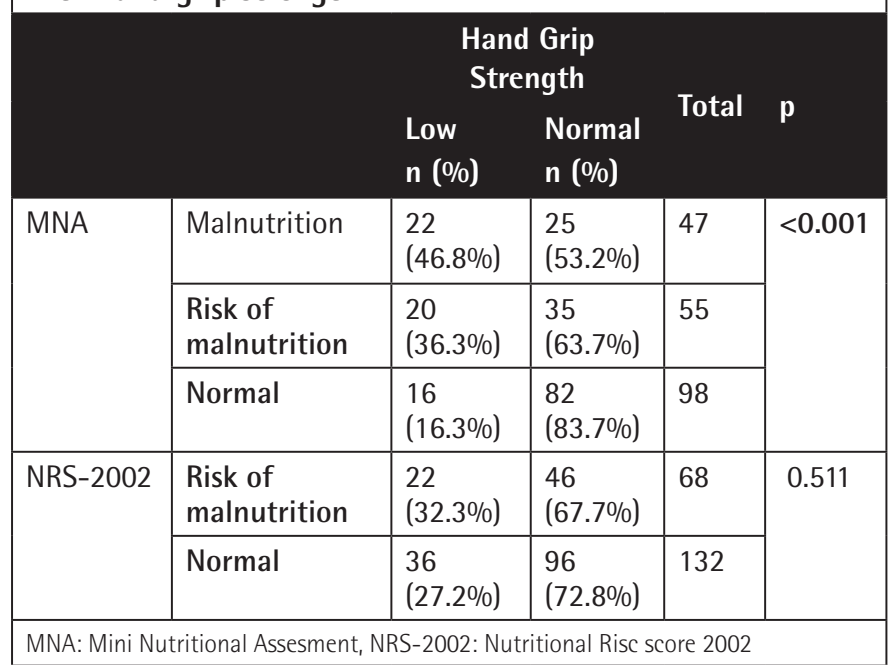


The MNA was found to have a sensitivity of $82 \%$ and a specificity of $90 \%$. MNA-SF was found to have a sensitivity of $83 \%$ and a specificity of 78\%. The NRS-2002 test was found to have a sensitivity of $80 \%$ and a specificity of $83 \%$. The positive predictive value of the NRS-2002 test was found to 0.83 , and the MNA-SF was 0.82 ; the MNA test 0.90 . The sensitivity and specificity analyses of MNA, MNA-SF and NRS-2002 tests were given at Table 4.

\section{Discussion}

Malnutrition is an important Geriatric syndrome which is seen in the high prevalence of geriatric population and causes serious morbidity and mortality. The meta analyse of Kaiser and et al. (10) which includes 24 studies and total 4507 patients from 12 countries found $31 \%$ and $5.8 \%$ malnutrition in the community. In our country, the risk of malnutrition on the geriatric policlinic was found 28\% patients in the study of Ulger et al. and 31\% in the study of Saka et al. $(11,12)$. By the Academic Geriatrics Association planned "Turkey Nursing Homes and Nursing Homes Nutritional Status Assessment Project" examined 14 nursing homes/hospices. Project results found that malnutrition risk was $38.3 \%$ and malnutrition was $11.9 \%$ at nursing home/hospices (12). Malnutrition incidence was found $30-60 \%$ in hospitalized geriatric patients (13-15). In our study, the incidence of malnutrition and malnutrition are similar to other studies.

In our study, 53 of 253 patients were excluded due to noncompliance to the tests. This can be statistically misleading because the tests have been performed on selected patients. This allows us Screening tests can't use alone for the diagnosis of malnutrition and not be suitable for all inpatients. Therefore, clinical and laboratory evaluations should be used for diagnosis and evaluation of malnutrition. Similar to our study, 108 of 520 patients were excluded because of similar non-compliance to the tests in Kagansky's study (16).

According to MNA score results, mean BMI was $30.3 \pm 5.8 \mathrm{~kg} / \mathrm{m}^{2}$ patients with normal nutritional status, $28.3 \pm 6.4$ in malnutrition risk and $24.4 \pm 5.9$ in malnutrition $(p<0.001)$. According to NRS-2002, these values were $29.5 \pm 6.4$ in the patients with normal nutrition and $26.1 \pm 5.7$ in the malnutrition risk group $(p<0.001)$. In other words, as the BMI decreased, the risk of malnutrition and malnutrition increased.

Calf circumference measurement is a parameter that can show total muscle mass and physical function (17). Drescher et al. (18) found a significant relationship between MNA and NRS-2002 with CC measurement $(p<0.0001$ and $p=0.001$, respectively) and stated that they were a valid parameter in the detection of malnutrition. In our study, there was a significant correlation between MNA-SF, MNA and NRS-2002 with CC, $(p<0.001$, $p<0.001, p=0.004)$. Therefore, CC measurement is an alone significant parameter in malnutrition screening.

Upper arm circumference measurement is a parameter that shows total body muscle ratio and physical function (19). Alert et al. (20) found a significant relationship between UAC and MNA. Also Cuervo et al. (21) found a significant relationship between MNA and UAC and stated that the UAC can be used in the screening of malnutrition. In our study, a significant relationship was found between MNA-SF, MNA and NRS2002 with UAC $(p<0.001, p<0.001, p=0.002)$. Thus the upper arm circumference is also an alone significant parameter in malnutrition screening.

Matos et al. (22) compared MNA with hand grip test, concluded that hand grip test can be used as a significant marker in the diagnosis of malnutrition. In our study, while there was a significant correlation between hand grip test and MNA-SF and MNA ( $p<0.001)$, no significant relationship was found with NRS-2002 ( $p=0.511)$. Therefore, the hand grip test can be used in malnutrition screening.

\begin{tabular}{|c|c|c|c|}
\hline & Sensitivity & Specificity & $\begin{array}{l}\text { Positive } \\
\text { predictive value }\end{array}$ \\
\hline MNA-SF & $83 \%$ & $78 \%$ & 0.82 \\
\hline MNA & $82 \%$ & $90 \%$ & 0.90 \\
\hline NRS-2002 & $80 \%$ & $83 \%$ & 0.83 \\
\hline
\end{tabular}

\begin{tabular}{|c|c|c|c|c|c|c|c|c|c|}
\hline & & \multicolumn{4}{|l|}{ UAC } & \multicolumn{4}{|l|}{ CC } \\
\hline & & $\begin{array}{l}\text { Low } \\
\text { n(\%) }\end{array}$ & $\begin{array}{l}\text { Normal } \\
n(\%)\end{array}$ & Total & $\mathbf{p}$ & $\begin{array}{l}\text { Low } \\
\text { n(\%) }\end{array}$ & $\begin{array}{l}\text { Normal } \\
n(\%)\end{array}$ & Total & p \\
\hline \multirow[t]{2}{*}{ MNA } & Malnutrition & $25(53.2 \%)$ & $22(46.8 \%)$ & 47 & \multirow[t]{2}{*}{$<0.001$} & $33(70.2 \%)$ & $14(29.8 \%)$ & 47 & \multirow[t]{2}{*}{$<0.001$} \\
\hline & Risk of malnutrition & $13(23.6 \%)$ & $42(77.4 \%)$ & 55 & & $19(34.5 \%)$ & $36(65.5 \%)$ & 55 & \\
\hline NRS-2002 & Normal & $23(17.4 \%)$ & $109(82.6 \%)$ & 132 & 0.002 & 44 (33.3\%) & $88(66.7 \%)$ & 132 & 0.004 \\
\hline
\end{tabular}


We compared the MNA-SF, MNA and the NRS-2002 Screening test in order to show the level of malnutrition which was tested by malnutrition screening. There was a significant correlation between MNA and MNA-SF and NRS-2002 Screening test results $(p<0.001)$. In this case, both MNA-SF and MNA could be used as NRS-2002 in hospitalized patients. Similar results were also found in other study that MNA, NRS 2002 and Malnutrition Universal Screening Tool (MUST) tests were examined in relation with sarcopenia in the hospitalized patients. Patients were divided into two groups under 65 years of age and above and MNA was associated with sarcopenia in both groups (23).

The patients that results of MNA-SF diagnosed normal, malnutrition or malnutrition risk, MNA also received similar diagnoses as $82 \%$ sensitive, $100 \%$ selective and 100\% positive predictive value.

In 22 of 55 patients who had malnutrition risk according to MNA, malnutrition risk was determined with NRS-2002. NRS2002 accepted normal 33 patients (63\%) as false normal.

NRS-2002 detected malnutrition risk in $16(17 \%)$ of 98 patients who were found to be normal according to MNA. According to this, NRS-2002 was $80 \%$ sensitive, $83 \%$ specific and $83 \%$ positive predictive value.

Based on these comparisons, the MNA had a sensitivity of $82 \%$ and a specificity of 90\%; The MNA-SF had a sensitivity of $83 \%$ and a specificity of 78\%; The NRS-2002 test was found to have a sensitivity of $80 \%$ and a specificity of $83 \%$. The positive predictive value of the NRS-2002 test was 0.83 , and the MNASF was 0.82 ; The MNA was 0.90 .

Neelemaat and et al. (24) study compared MNA-SF, NRS-2002, Malnutrition Screening Tool (MST), SNAQ and MUST Screening tests and no superiority was found between tests.

Similarly, in a study involving eight centers in China, MNA and NRS-2002 were compared with biochemical parameters and length of hospital stay. It has been shown that both tests can be used for malnutrition screening in inpatients and may be associated with length of stay (25).

In Drescher et al. (26) study were compared MNA and NRS2002, reported that NRS-2002 was a Superior test for the detection of malnutrition in inpatients in geriatric clinic. MNA was found to be an independent predictor of survival in patients according to second generation anti-psychotic in a study of patients with heart failure. In the same study MNA-SF had the best sensitivity and specificity for screening malnutrition compared the MUST and MST (27). In the other study, MNASF, MUST and NRS 2002 were found adequate in assessing malnutrition in hip fracture operated elderly patients. In addition, MNA-SF predicted readmissions and mortality (28). In our study, the MNA was concluded to be superior to the other tests (82\% sensitivity, $90 \%$ specificity).
As a result, it was determined that MNA and MNA-SF which are used in malnourished policlinic patients can be used in inpatients such as NRS 2002. More randomized controlled trials are needed to predict which test can be used for better malnutrition screening. At the same time we think that the hand grip strength and anthropometric measurements are reliable parameters malnutrition screening and evaluation.

\section{Ethics}

Ethics Committee Approval: Istanbul University Cerrahpaşa Faculty of Medicine Clinical Research Ethics Committee was approved with the decision number 1834 dated 18.03.2013.

Informed Consent: Informed consent of patients were obtained.

Peer-review: Externally and internally peer-reviewed.

\section{Authorship Contributions}

Surgical and Medical Practices: H.Y., E.D, A.D., D.S.E., Concept: H.Y., E.D, A.D., D.S.E., A.E, Design: H.Y., T.E, E.D, A.D., D.S.E., Data Collection or Processing: H.Y., T.E, E.D, A.E., Analysis or Interpretation: H.Y., T.E, E.D, Literature Search: H.Y., T.E, E.D, Writing: H.Y., T.E.

Conflict of Interest: No conflict of interest was declared by the authors.

Financial Disclosure: The authors declared that this study received no financial support.

\section{References}

1. Jong N. Nutrition and senescence: Healthy aging for all in the new millennium. Nutrition. 2000;16:537-541.

2. Heinrich $M$, Prieto J. Will we globalise local knowledge systems? Ageing Research Reviews. 2007;7:249-274.

3. Lochs H, Allison SP, Meier R, Pirlich M, Kondrup J, Schneider S, van den Berghe G, Pichard C. Introductory to the ESPEN Guidelines on Enteral Nutrition: Terminology, definitions and general topics. Clin Nutr. 2006;25:180-186.

4. Smith AP. The concept of well-being: Relevance to nutrition research. Br. J. Nutr. 2005;93:1-5

5. Ülger Z, Halil M, Kalan I, Yavuz BB, Cankurtaran M, Güngör E, Arioğul S. Comprehensive assessment of malnütrition risk and related factors in a large group of community-dwelling older adults. Clin Nutr. 2010;29:507511.

6. Mitchell CO. Nutritional assessment of the elderly in: Geriatric nutrition the health professionals Handbook. 2nd edition, Aspen Publishers, Gaithersburg 1999, pp 382-415

7. Abellan van Kan G. Epidemiology and consequences of sarcopenia. J. Nutr. Health Aging. 2009:13;708-712.

8. Cederholm T, Bosaeus I, Barazzoni R, Bauer J, Van Gossum A, Klek S Muscaritoli M, Nyulasi I, Ockenga J, Schneider SM, de van der Schueren MA, Singer P. Diagnostic criteria for malnutrition - An ESPEN Consensus Statement. Clin Nutr. 2015;34:335-340.

9. CederholmT, JensenGL, Correia M, Gonzalez MC, Fukushima R, Higashiguchi T, Baptista G, Barazzoni R, Blaauw R, Coats A, Crivelli A, Evans DC, Gramlich L, Fuchs-Tarlovsky V, Keller H, Llido L, Malone A, Mogensen KM, Morley JE, Muscaritoli M, Nyulasi I, Pirlich M, Pisprasert V, de van der Schueren MAE, Siltharm S, Singer P, Tappenden K, Velasco N, Waitzberg D, Yamwong 
P, Yu J, Van Gossum A, Compher C; GLIM Core Leadership Committee; GLIM Working Group. GLIM criteria for the diagnosis of malnutrition - A consensus report from the global clinical nutrition community. Clin Nutr. 2019;10:207-217.

10. Kaiser MJ, Bauer JM, Ramsch C, Uter W, Guigoz Y, Cederholm T, Thomas DR, Anthony PS, Charlton KE, Maggio M, Tsai AC, Vellas B, Sieber CC, for the Mini Nutritional Assessment International Group. Frequency of malnutrition in older adults: A multinational perspective using the mini nutritional assessment. J Am Geriatr Soc. 2010;58:1734-1738.

11. Chidester JC, Spangler AA. Fluid intake in the institutionalized elderly. J Am Diet Assoc. 1997;97:23-28.

12. Cankurtaran $M$, Saka $B$, Sahin $S$, Varlı M, Döventaş $A$, Yavuz BB, Halil M, Curgunlu A, Ulger Z, Tekin N, Akcicek F, Karan MA, Atlı T, Beger T, Erdinçler DS, Arıoğul S. Sarcopenia assessment project in the nursing homes in Turkey. Eur J Clin Nutr. 2014;68:690-694.

13. Kondrup J, Rasmussen HH, Hamberg O, Stanga Z; Ad Hoc ESPEN Working Group. Nutritional risk screening (NRS 2002): a new method based on an analysis of controlled clinical trials. Clin Nutr. 2003;22:321-236.

14. Poulia KA, Yannakoulia M, Karageorgou D, Gamaletsou M, Panagiotakos DB, Sipsas NV, Zampelas A. Evaluation of the efficacy of six nutritional screening tools to predict malnutrition in the elderly. Clin Nutr. 2012;31:378-385.

15. Kondrup J, Allison SP, Elia M, Vellas B, Plauth M. ESPEN guidelines for nutrition screening 2002. Clin Nutr. 2003;22:415-421.

16. Kagansky N, Berner Y, Koren-Morag N, Perelman L, Knobler H, Levy S. Poor nutritional habits are predictors of poor outcome in very old hospitalized patients. Am J Clin Nutr. October 2005;82:784-791.

17. Guigoz Y, Lauque $S$, Vellas BJ. Identifying the elderly at risk for malnutrition: The mini nutritional assessment. Clin Geriatr Med. 2002;18:737-757.

18. Drescher T, Singler K, Ulrich A, Koller M, Keller U, Christ-Crain M, Kressig RW. Comparison of two malnutrition risk screening methods and their association with markers of protein malnutrition in geriatric hospitalized patients. European Journal of Clinical Nutrition. 2010;64:887-893.

19. Elia M, Stroud M. Nutrition in acute care. Clin Med. 2004;4:405-407.

20. Alert PD, Villaroel MR, Casas VN, Farre VC. Assessing risk screening methods of malnutrition in geriatric patients; mini nutritional assessment versus geriatric nutritional risk index. Nutr Hosp. 2012;27:590-598.
21. Cuervo M, Ansorena D, García A, González Martínez MA, Astiasarán I, Martinez JA. Assessment of calf circumference as an indicator of the risk for hyponutrition in the elderly Nutr Hosp. 2009;24:63-67.

22. Matos $\sqcup$, Amaral TF. Handgrip strength as a hospital admission nutritional risk screening method. European Journal of Clinical Nutrition. 2007;61:11281135.

23. Yürüyen $M$, Yavuzer $H$, Yavuzer $S$, Cengiz $M$, Demirdağ $F$, Kara $Z$, Avcl $S$, Yurttaş N, İslamoğlu M, İmre E, Taşkın A, Döventaş A, Erdinçler U. Comparison of nutritional risk screening tools for predicting sarcopenia in hospitalized patients. Turkish Journal of Medical Sciences. 2017;47:1362-1369.

24. Neelemaat $F$, Meijers J, Kruizenga $H$, van Ballegooijen $H$, van Bokhorst-de van der Schueren M. Comparison of five malnutrition screening tools in one hospital inpatient sample. J Clin Nurs. 2011;20: 2144-2152.

25. Miao JP, Quan XQ, Zhang CT, Zhu H, Ye M, Shen LY, Guo OH, Zhu GY, Mei $\mathrm{OJ}, \mathrm{Wu}$ YX, Li SG, Zhou HL. Comparison of two malnutrition risk screening tools with nutritional biochemical parameters, BMI and length of stay in Chinese geriatric inpatients: a multicenter, cross-sectional study. BMJ Open. 2019;9:e022993.

26. Drescher T, Singler K, Ulrich A, Koller M, Keller U, Christ-Crain M, Kressig RW. Comparison of two malnutrition risk screening methods (MNA and NRS 2002) and their association with markers of protein malnutrition in geriatric hospitalized patients. European Journal of Clinical Nutrition. 2010;64:887-893.

27. Joaquin $C$, Puig $R$, Gastelurrutia $P$, Lupón J, de Antonio $M$, Domingo $M$, Moliner $\mathrm{P}$, Zamora E, Martin M, Alonso N, Puig-Domingo M, Bayes-Genis A. Mini nutritional assessment is a better predictor of mortality than subjective global assessment in heart failure out-patients. Clinical Nutrition. 2019;38:2740-2746.

28. Koren-Hakim T, Weiss A, Hershkovitz A, Otzrateni I, Anbar R, Gross Nevo RF, Schlesinger A, Frishman S, Salai M, Beloosesky Y. Comparing the adequacy of the MNA-SF, NRS-2002 and MUST nutritional tools in assessing malnutrition in hip fracture operated elderly patients. Clinical Nutrition. 2016;35:1053-1058. 